\title{
Choice of Methodology Impacts Outcome in Indirect Comparisons of Drugs for Idiopathic Pulmonary Fibrosis
}

\author{
David A. Scott ${ }^{1}$, Emma Loveman ${ }^{2, *(\mathbb{C})}$, Jill L. Colquitt ${ }^{2}$ and Katherine $\mathrm{O}^{\prime}$ Reilly $^{3}$ \\ 1 Diabetes Research Centre, College of Life Sciences, University of Leicester, Leicester Diabetes Centre, \\ Leicester General Hospital, Gwendolen Road, Leicester LE5 4PW, UK \\ 2 Effective Evidence LLP, 26 The Curve, Waterlooville, Hampshire PO8 9SE, UK \\ 3 Department of Respiratory Medicine, Mater Misericordiae University Hospital, Eccles St., \\ D07 R2WY Dublin, Ireland \\ * Correspondence: emma.loveman@effectiveevidence.org; Tel.: +44-239-259-9594
}

Received: 12 June 2019; Accepted: 30 July 2019; Published: 6 August 2019

\begin{abstract}
Background and Objectives: Idiopathic pulmonary fibrosis (IPF) is a chronic condition leading to lung damage and deterioration in lung function. Following the availability of two new drugs, nintedanib and pirfenidone, a number of network meta-analyses (NMAs) of randomised controlled trials have been published which have conducted indirect comparisons on the two drugs. Differing recommendations from these studies are potentially confusing to clinicians and decision-makers. We aimed to systematically review published NMAs of IPF treatments, to compare their findings and summarise key recommendations. Materials and Methods: We systematically reviewed (PROSPERO: CRD42017072876) six eligible NMAs and investigated the differences in their findings with respect to key endpoints. We focused on differences in head-to-head comparisons between nintedanib and pirfenidone. Results: The NMAs were broadly consistent, with most differences being explained by model choice, endpoint definitions, inclusion of different studies, different follow-up durations, and access to unpublished data. A substantive difference remained, however, in the change from baseline forced vital capacity (FVC). One NMA favoured nintedanib, another found no statistical difference, whilst others did not conduct the analysis. These differences can be attributed to the choice of methodology, the use of the standardised mean difference (SMD) scale, and population heterogeneity. Conclusions: NMA methods facilitated the comparison of nintedanib and pirfenidone in the absence of a head-to-head trial. However, further work is needed to determine whether the trial populations are homogeneous and whether the SMD is appropriate in this population. Differences in patient characteristics may obscure the difference in treatment effects. To assist decision-makers, an exploration of efficacy in real-world populations may be prudent.
\end{abstract}

Keywords: idiopathic pulmonary fibrosis; network meta-analysis; indirect comparisons; nintedanib; pirfenidone

\section{Introduction}

Idiopathic pulmonary fibrosis (IPF) is a chronic condition leading to progressive deterioration in lung function and respiratory failure [1]. IPF has a poor prognosis with a median survival from diagnosis of 2-5 years. Two drugs in a new class (anti-fibrotics), pirfenidone and nintedanib, have been shown to slow the deterioration in lung function when compared to placebo. However, there is no direct head-to-head trial evidence of their relative effectiveness to guide prescribers. Hence, comparisons of these treatments have been facilitated through indirect comparisons. 
Published indirect comparisons of pirfenidone and nintedanib have some inconsistencies in their findings and the reasons for these differences have not been examined. We aimed to systematically review published indirect comparisons comparing pirfenidone and nintedanib and explore reasons for the differences in results. The findings elucidate the current uncertainty regarding the relative effectiveness of pirfenidone and nintedanib, and can be used to assist patients, clinicians, and policy-makers with treatment choices.

\section{Materials and Methods}

Accepted methods for searching, study selection, data extraction, and risk of bias assessment were pre-stated in our registered protocol (https://www.crd.york.ac.uk/prospero/display_record.php? RecordID=72876). We identified articles by searches of MEDLINE, EMBASE, and the Cochrane Library and the through checking of reference lists of included studies. There were no language restrictions and searches were conducted by an experienced information scientist. We included indirect comparisons and network meta-analyses (NMAs) of available interventions for people with a confirmed diagnosis of IPF.

Indirect treatment comparisons compare results from trials via a common comparator, maintaining randomisation between treatments within each trial [2]. The principal is illustrated in Figure 1.

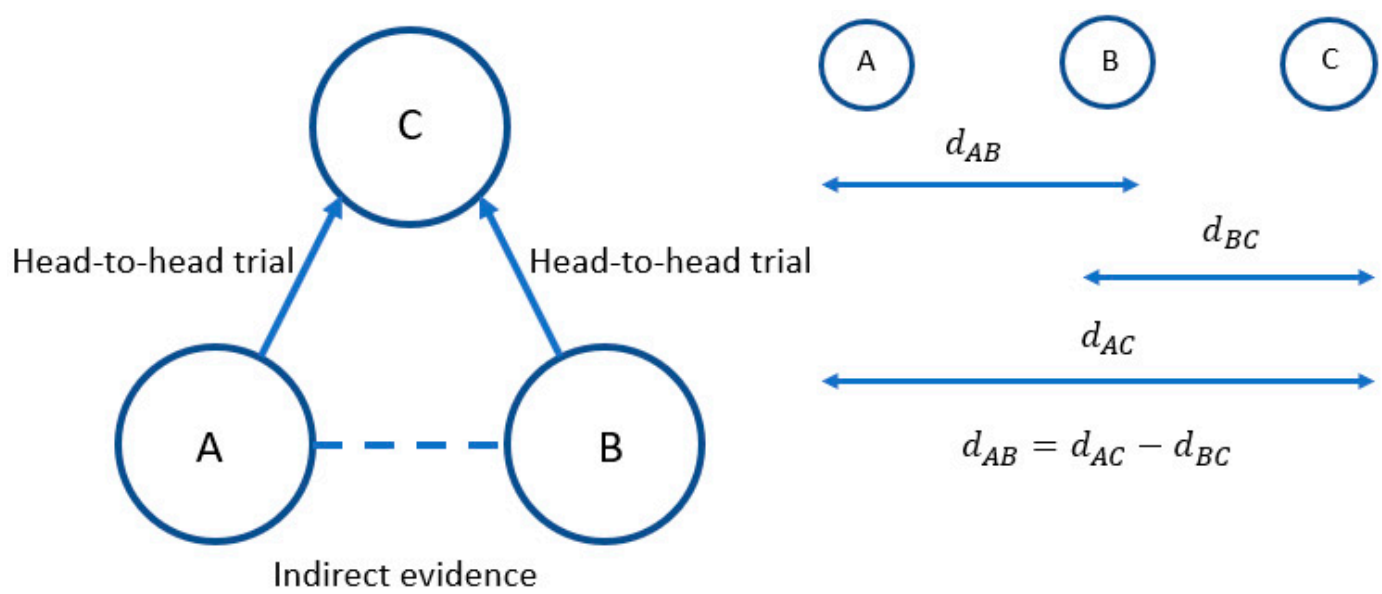

Figure 1. The principles of indirect comparisons.

In this simple illustration, there are head-to-head trials comparing treatment $A$ to treatment $C$ and treatment $B$ to treatment $C$, but no trials comparing treatment $A$ to treatment $B$. Hence, an indirect comparison must be made to compare treatments $\mathrm{A}$ and $\mathrm{B}$.

The relative treatment effect (e.g., log odds ratio or mean difference) for treatment $\mathrm{A}$ compared to $B$ is represented by $d_{A B}$, treatment $B$ compared to $C$ by $d_{B C}$, and treatment $A$ compared to treatment $C$ by $d_{A C}$. Whilst we have estimates of $d_{A C}$ and $d_{B C}$ from head-to-head trials, we do not know $d_{A B}$. However, under the properties of indirect comparisons this can be calculated by subtracting $\mathrm{d}_{\mathrm{BC}}$ from $\mathrm{d}_{\mathrm{AC}}$, as indicated.

NMA extends the indirect comparison concept to networks of trials of direct evidence and indirect evidence, allowing us to add and subtract relative treatment effects to compare all alternative treatments of interest in a single coherent analysis for each outcome [3]. These methods are increasingly being used for healthcare decision-making [4].

NMA can be conducted using frequentist or Bayesian approaches depending upon the software package used. Bayesian analyses use Markov chain Monte Carlo (MCMC) methods, combining prior distributions with the data to construct a posterior distribution upon which to base all summary results [5].

As with traditional pairwise meta-analysis, fixed or random effects models can be used. Whilst variation between studies in a fixed effects model is attributable to statistical chance, in random effect 
it is attributed to between-study heterogeneity [6]. Heterogeneity can also be adjusted for by including study or population characteristics using meta-regression [7].

The primary outcomes were survival, lung function/capacity, and adverse events. The literature search results were screened by two independent reviewers to identify all citations that may meet the inclusion criteria. Full manuscripts of selected citations were retrieved and assessed by two reviewers against the eligibility criteria. Any disagreements over study inclusion were resolved by consensus.

Two reviewers extracted data from the included NMAs into a previously piloted form to avoid any errors. The methodological quality of the included NMAs was assessed, focusing on the core principles of heterogeneity and inconsistency. The analysis is said to be consistent if the direct and indirect evidence is consistent, i.e., $\mathrm{d}_{\mathrm{AB}}=\mathrm{d}_{\mathrm{AC}}-\mathrm{d}_{\mathrm{BC}}$. Any disagreements between reviewers was resolved by consensus.

The unit of analysis for this systematic overview was the NMA, not the individual trials they contained. Therefore, we did not conduct any new analyses, but conducted a narrative synthesis of the methods, outcomes, and data from the NMAs.

\section{Results}

We searched nine electronic databases and identified 18,125 unique records. After screening titles and abstracts we identified 90 reviews and retrieved full papers for 18 of these that had a pairwise meta-analysis or NMA. Five NMAs published between 2014 and 2017 were included [8-12]. We also identified a poster presentation of a sixth NMA published in 2018 [13]. The randomised controlled trials (RCTs) included by each of the six NMAs are presented in Table 1, and the baseline characteristics of the individual RCTs are summarised in Table 2.

Figure 2 shows the evidence network of 10 RCTs featuring pirfenidone and nintedanib studies. Studies included in the six NMAs differed and two did not connect to the network as there was no common comparator. Commonly reported endpoints were forced vital capacity (FVC), all-cause mortality, and respiratory mortality. The FVC endpoint was measured on two continuous and one binary scale, see Table 1.
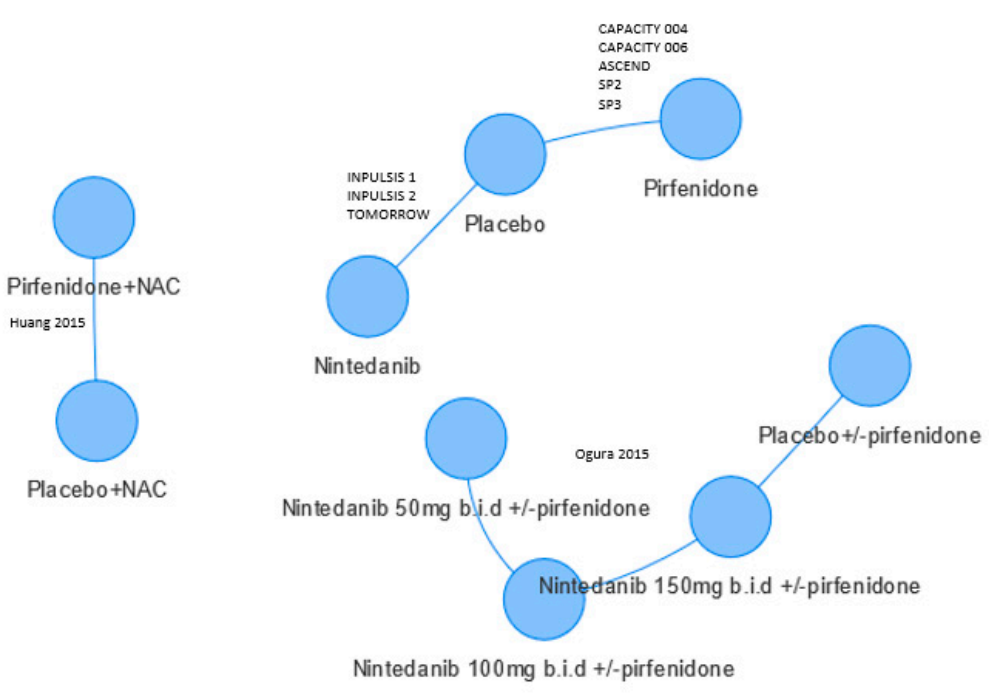

Figure 2. Evidence network. Only Skandamis [13] included Huang 2015 [14] and Ogura 2015 [15]. Some patients in Ogura 2015 received nintedanib and pirfenidone. Circles refer to treatments being compared and may include more than one trial. 
Table 1. Randomised controlled trials (RCTs) included in each of the network meta-analyses (NMAs) (for at least one outcome)

\begin{tabular}{|c|c|c|c|c|c|c|}
\hline \multirow{3}{*}{$\begin{array}{c}\text { Relevant RCTs of Nintedanib } \\
\text { or Pirfenidone } \\
\begin{array}{c}\text { Trial Name, Phase, Forced Vital } \\
\text { Capacity (FVC) Outcome, } \\
\text { and Timepoints }\end{array}\end{array}$} & \multicolumn{6}{|c|}{ Inclusion of RCTs (for at Least One Outcome) in the NMAs } \\
\hline & \multicolumn{6}{|c|}{ NMA } \\
\hline & $\begin{array}{c}\text { Fleetwood, } 2017 \text { [9] } \\
\text { Bayesian Markov chain } \\
\text { Monte Carlo (MCMC) } \\
\text { Methods, Random Effects }\end{array}$ & $\begin{array}{c}\text { Rochwerg, } 2016 \text { [12] } \\
\text { Bayesian MCMC } \\
\text { Methods, Random } \\
\text { Effects }\end{array}$ & $\begin{array}{c}\text { Canestaro, } 2016[8] \\
\text { Bayesian MCMC } \\
\text { Methods, Fixed } \\
\text { Effects }\end{array}$ & $\begin{array}{c}\text { Loveman } 2015[10] \\
\text { Bayesian MCMC } \\
\text { Methods, Fixed } \\
\text { Effects }\end{array}$ & $\begin{array}{c}\text { Loveman } 2014 \text { [11] } \\
\text { Bayesian MCMC } \\
\text { Methods, Fixed } \\
\text { Effects }\end{array}$ & $\begin{array}{c}\text { Skandamis } 2018[13] \\
\text { (poster only) Bayesian } \\
\text { MCMC Methods, } \\
\text { Random Effects }\end{array}$ \\
\hline $\begin{array}{l}\text { SP3 [16], Phase II \% predicted at } \\
52 \text { weeks }{ }^{\text {a }} \text {, Litres at } 36 \text { weeks }\end{array}$ & $\checkmark^{b}$ & $\checkmark$ & $\checkmark$ & $\checkmark$ & $\checkmark$ & $\checkmark$ \\
\hline $\begin{array}{l}\text { SP2 [17], Phase III \% predicted at } \\
52 \text { weeks }{ }^{\text {a }} \text {; Litres at } 52 \text { weeks }\end{array}$ & $\checkmark^{b}$ & $\checkmark$ & $\checkmark$ & $\checkmark$ & $\checkmark$ & $\checkmark$ \\
\hline $\begin{array}{c}\text { Capacity } 004 \text { [18], Phase III \% } \\
\text { predicted at } 72 \text { weeks; Litres at } 48 \\
\text { and } 52 \text { weeks a }\end{array}$ & $\checkmark^{b}$ & $\checkmark^{c}$ & $\checkmark^{c}$ & $\checkmark$ & $\checkmark$ & $\checkmark$ \\
\hline $\begin{array}{c}\text { Capacity } 006 \text { [18], Phase III \% } \\
\text { predicted at } 72 \text { weeks; Litres at } 48 \\
\text { and } 52 \text { weeks a }\end{array}$ & $\checkmark^{\mathrm{b}}$ & $\checkmark^{c}$ & $\checkmark^{c}$ & $\checkmark$ & $\checkmark$ & $\checkmark$ \\
\hline $\begin{array}{l}\text { ASCEND [19], Phase III \% predicted } \\
\text { at } 52 \text { weeks }{ }^{\text {a }} \text {; Litres at } 52 \text { weeks }\end{array}$ & $\checkmark^{b}$ & $\checkmark$ & $\checkmark$ & $\checkmark$ & Not included & $\checkmark$ \\
\hline $\begin{array}{l}\text { TOMORROW [20], Phase III \% } \\
\text { predicted at } 52 \text { weeks; Litres at } \\
52 \text { weeks }\end{array}$ & $\checkmark$ & $\checkmark$ & $\checkmark$ & $\checkmark$ & $\checkmark$ & $\checkmark$ \\
\hline $\begin{array}{l}\text { INPULSIS } 1 \text { [21], Phase II \% } \\
\text { predicted at } 52 \text { weeks; Litres at } \\
52 \text { weeks }\end{array}$ & $\checkmark$ & $\checkmark^{c}$ & $\checkmark^{c}$ & $\checkmark$ & Not included & $\checkmark$ \\
\hline $\begin{array}{c}\text { INPULSIS } 2 \text { [21], Phase II \% } \\
\text { predicted at } 52 \text { weeks; Litres at } \\
52 \text { weeks }\end{array}$ & $\checkmark$ & $\checkmark^{c}$ & $\checkmark^{c}$ & $\checkmark$ & Not included & $\checkmark$ \\
\hline $\begin{array}{l}\text { Huang, } 2015 \text { [14] Phase II Litres at } \\
48 \text { weeks; \% predicted at } 48 \text { weeks }\end{array}$ & Not included & Not included & Not included & Not included & Not included & $\checkmark$ \\
\hline $\begin{array}{l}\text { Ogura, } 2015 \text { [15] Phase II } \\
\text { Not reported }\end{array}$ & Not included & Not included & Not included & Not included & Not included & $\checkmark$ \\
\hline
\end{tabular}

Unpublished data; ${ }^{b}$ Utilised unpublished forced vital capacity (FVC) data from the manufacturer; ${ }^{\mathrm{c}}$ Unclear whether Capacity 004 and 006, and INPULSIS 1 and 2 were each included as two separate trials by the NMA. 
Table 2. Characteristics of RCTs included in the NMAs.

\begin{tabular}{|c|c|c|c|c|c|c|c|c|}
\hline Trial Name, Phase & Intervention, $\mathrm{n}$ & Comparator, $\mathbf{n}$ & $\begin{array}{c}\text { Duration of } \\
\text { Treatment }\end{array}$ & Mean Age & $\%$ Male & $\begin{array}{l}\text { Time Since } \\
\text { Diagnosis }\end{array}$ & $\begin{array}{c}\text { Mean \% } \\
\text { Predicted FVC }\end{array}$ & Risk of Bias ${ }^{a}$ \\
\hline SP3 [16], Phase II & $\begin{array}{l}\text { Pirfenidone } 1800 \\
\text { mg/day, } n=73\end{array}$ & Placebo, n = 36 & 39 weeks & 64 & 90 & $<1$ year: $22 \%$ & 80 & Unclear \\
\hline SP2 [17], Phase III & $\begin{array}{l}\text { Pirfenidone } 1800 \\
\mathrm{mg} / \text { day, } \mathrm{n}=108\end{array}$ & Placebo, $\mathrm{n}=104$ & 52 weeks & 65 & 78 & $<1$ year: $37 \%$ & 78 & Unclear \\
\hline Capacity 004 [18], Phase III & $\begin{array}{c}\text { Pirfenidone } 2403 \\
\text { mg/day, } \mathrm{n}=174\end{array}$ & Placebo, n = 174 & 72 weeks & 66 & 71 & $\leq 1$ year: $48 \%$ & 75 & Low \\
\hline Capacity 006 [18], Phase III & $\begin{array}{l}\text { Pirfenidone } 2403 \\
\mathrm{mg} / \text { day, } \mathrm{n}=171\end{array}$ & Placebo, $\mathrm{n}=173$ & 72 weeks & 67 & 72 & $\leq 1$ year: $59 \%$ & 74 & Low \\
\hline ASCEND [19], Phase III & $\begin{array}{c}\text { Pirfenidone } 2403 \\
\text { mg/day, } n=278\end{array}$ & Placebo, n = 277 & 52 weeks & 68 & 78 & 1.7 years & 68 & Low \\
\hline TOMORROW [20], Phase III & $\begin{array}{c}\text { Nintedanib } 300 \mathrm{mg} / \text { day, } \\
\mathrm{n}=85\end{array}$ & Placebo, n = 85 & 52 weeks & 65 & 75 & 1.2 years & 80 & Low \\
\hline INPULSIS 1 [21], Phase II & $\begin{array}{c}\text { Nintedanib } 300 \mathrm{mg} / \text { day, } \\
\mathrm{n}=309\end{array}$ & Placebo, n = 204 & 52 weeks & 67 & 81 & 1.7 years & 80 & Low \\
\hline INPULSIS 2 [21], Phase II & $\begin{array}{c}\text { Nintedanib } 300 \mathrm{mg} / \text { day, } \\
\mathrm{n}=329\end{array}$ & Placebo, n = 219 & 52 weeks & 67 & 78 & 1.6 years & 79 & Low \\
\hline Huang 2015 [14], Phase II & $\begin{array}{c}\text { Pirfenidone } 1800 \\
\mathrm{mg} / \text { day }+ \text { NAC, } \mathrm{n}=38\end{array}$ & $\begin{array}{c}\text { Placebo + NAC, } \\
\mathrm{n}=38\end{array}$ & 48 weeks & 60 & 93 & Not reported & 77 & Unclear \\
\hline Ogura 2015 [15], Phase II & $\begin{array}{c}\text { Nintedanib }{ }^{\text {b }} 100 \\
\text { mg/day, } \mathrm{n}=6 ; 200 \\
\text { mg/day, } \mathrm{n}=8 ; 300 \\
\text { mg/day, } \mathrm{n}=24\end{array}$ & Placebo $^{b}, \mathrm{n}=12$ & up to 28 days & 65 & 70 & Not reported & 74 & Unclear \\
\hline
\end{tabular}

${ }^{a}$ Risk of selection bias. ${ }^{\mathrm{b}}$ A proportion of patients also received pirfenidone. NAC: N-acetylcysteine. 
Table 3. NMA base case results of nintedanib vs. pirfenidone comparisons (reciprocal calculated where necessary), WMD or OR (95\% Crl).

\begin{tabular}{|c|c|c|c|c|c|c|}
\hline \multirow[b]{2}{*}{ Outcome } & \multicolumn{6}{|c|}{ NMA } \\
\hline & $\begin{array}{c}\text { Fleetwood, 2017 [9] } \\
\text { Bayesian MCMC } \\
\text { Methods, Random Effects }\end{array}$ & $\begin{array}{c}\text { Rochwerg, } 2016[12] \\
\text { Bayesian MCMC } \\
\text { Methods, Random Effects }\end{array}$ & $\begin{array}{c}\text { Canestaro, } 2016[8] \\
\text { Bayesian MCMC } \\
\text { Methods, Fixed Effects }\end{array}$ & $\begin{array}{c}\text { Loveman } 2015[10] \\
\text { Bayesian MCMC } \\
\text { Methods, Fixed Effects }\end{array}$ & $\begin{array}{c}\text { Loveman 2014 [11] } \\
\text { Bayesian MCMC } \\
\text { Methods, Fixed Effects }\end{array}$ & $\begin{array}{l}\text { Skandamis } 2018 \text { [13] (Poster } \\
\text { Only) Bayesian MCMC } \\
\text { Methods, Random Effects }\end{array}$ \\
\hline $\begin{array}{l}\text { Change in \% } \\
\text { predicted FVC }\end{array}$ & WMD $-0.23(-2.13,1.66)$ & Not estimated & Not estimated & OR $0.67(0.51,0.88)^{a}$ & OR $0.56(0.31,1.03)$ & Not estimated \\
\hline Change in FVC Litres & WMD $-0.01(-0.15,0.13)$ & Not estimated & Not estimated & & & Not estimated \\
\hline$>10 \%$ decline in FVC & OR $1.11(0.60,2.0)$ & Not estimated & OR $1.16(0.83,1.67)$ & OR $1.21(0.86,1.72)$ & Not estimated & OR $1.10(0.49,2.22)$ \\
\hline Mortality & OR $1.35(0.51,3.70)$ & OR $1.05(0.45,2.78)$ & OR $1.02(0.55,1.89)$ & OR $1.39(0.7,2.82)$ & Not estimated & OR $1.08(0.52,2.63)$ \\
\hline Respiratory mortality & Not estimated & Not estimated & $1.09(0.49,2.38)$ & OR $2.1(0.77,6.17)$ & Not estimated & Not estimated \\
\hline $\begin{array}{l}\text { Serious adverse } \\
\text { events }\end{array}$ & Not estimated & OR $1.04(0.51,2.24)$ & Not estimated & Not estimated & Not estimated & OR $0.98(0.62,1.61)$ \\
\hline
\end{tabular}

The statistically significant result is represented by bold font; ${ }^{\text {a }}$ converted from standardised mean difference (SMD) to OR using Chinn, 2000 [22]. CrI: credible interval; MCMC: Markov chain Monte Carlo; OR: odds ratio; WMD: weighted mean difference. 
Binary endpoints (proportion of patients achieving a $>10 \%$ decline in FVC, mortality, respiratory mortality, serious adverse events) used the odds ratio (OR) scale, and continuous endpoints (change in $\%$ predicted FVC and change in FVC litres) used weighted mean difference (WMD) or standardised mean difference (SMD).

The WMD is a weighted average of the difference in mean treatments effects. The SMD approach is used when trials assess the same outcome but measure it in different ways [23]. In this case the assumption is that the mean change in FVC \% predicted is measuring the same thing as litres change in FVC. The SMD approach converts these measures to a common scale. The mean difference between treatment arms is divided by the standard deviation; thus, effect measures are adjusted to be defined in terms of units of SD. SMD thus effectively changes the weights of studies in a meta-analysis. Since difficulties persist in how to interpret treatment effects on the SMD scale, these are converted to ORs using the following formulae from [22]:

$$
\begin{aligned}
\log O R & =\frac{\pi}{\sqrt{3}} S M D . \\
\operatorname{se}(\log O R) & =\frac{\pi}{\sqrt{3}} \operatorname{se}(S M D) .
\end{aligned}
$$

Bayesian Markov chain Monte Carlo (MCMC) methods were used in all NMAs.

Statistical heterogeneity in treatment effects was assessed in all NMAs; three discussed similarities across the network of studies and considered them to be sufficiently similar to be combined. One NMA was sponsored by the manufacturer of pirfenidone [9].

Choice of methodology differed between the NMAs (Table 3); Fleetwood [9], Rochwerg [12], and Skandamis [13] preferred a random effects model, Loveman et al., 2015 [10] and Loveman et al., 2014 [11] a fixed effects model, whilst Canestaro [8] presented both models.

\subsection{Forced Vital Capacity (FVC)}

Loveman et al., 2015 [10] reported a statistically significant difference in FVC in favour of nintedanib, whilst Fleetwood [9] and Loveman et al., 2014 [11] found no statistically significant difference between treatments. Three NMAs did not report this outcome. There were differences between the NMAs in the length of follow-up included from the trials and whether the FVC was reported as percentage predicted FVC or FVC in litres by the trials (Table 1). The percentage predicted FVC is based on population-based data of individuals of a certain height, age, and gender, and is sometimes additionally corrected for race.

\subsection{Other Endpoints}

There were no other statistically significant differences between nintedanib and pirfenidone. The proportion of patients with a $>10 \%$ decline in FVC was consistent across NMAs, with the random effects having a wider credible interval. The all-cause mortality analyses were similar.

\section{Discussion}

The main sources of differences in the results of the NMAs were the choice of statistical methodology and the data that were included. For FVC, Loveman et al. $[10,11]$ used the SMD approach previously used in IPF by King et al. [24] to combine the change in \% predicted FVC and change in FVC (litres). Hence, the underlying assumption is that mean change in $\mathrm{FVC} \%$ predicted measures the same outcome as litres change in FVC. Fleetwood [9] had access to unpublished mean change in FVC \% predicted and change in FVC litres, and thus was able to conducted separate analyses as well as additional follow-up data for all pirfenidone studies from the manufacturer (Table 1). Loveman et al., 2014 [11] was published prior to the availability of more recent data. 
For the categorical FVC analyses, differing data were used. Loveman et al., 2015 [10] used data from both Japanese studies of pirfenidone (SP2 and SP3), whereas only one of these (SP2) was used by Canestaro [8] and Fleetwood [9] included neither. Fleetwood used unpublished data for the ASCEND and CAPACITY trials of pirfenidone. Canestaro appeared to pool data from the INPULSIS and CAPACITY studies, which meant those studies were given a higher weight in their fixed effects analysis. Skandamis [13] included two RCTs that were published after searches were undertaken for the other five NMAs [14,15]. These two RCTs do not connect to the network (Figure 2).

The NMAs also included different data for all-cause mortality. For example, Loveman et al., 2015 used conference data from the Capacity trial that was not widely available [10]. Canestaro used data that was not reported in the trial publication of SP2 [8], Fleetwood used reanalysed data of the SP2/SP3 pirfenidone trials studies by Nathan et al. [25], and Canestaro included pooled data from the two INPULSIS studies. Differences are also explained by the use of a random effects model in Fleetwood [9]. Similarly, for respiratory mortality, the higher mean and wider credible intervals in Loveman et al., 2015 [10] compared to Canestaro [8] are explained by the use of use of conference data by Loveman et al., 2015 and the inclusion of pooled INPULSIS studies by Canestaro. Finally, serious adverse events were similar, albeit Skandamis [13] included two additional phase II RCTs.

\section{Limitations}

Sensitivity analysis for the risk of bias of each of the included RCTs was not undertaken, although no studies were considered to have a high risk of bias.

\section{Conclusions}

The lack of a head-to-head trial comparing nintedanib to pirfenidone has resulted in a number of studies attempting indirect comparison using an NMA approach. For most outcomes, including all-cause mortality, respiratory mortality, and the proportion of patients with a $>10 \%$ decline in FVC, the published indirect comparisons were broadly consistent in finding no meaningful difference between nintedanib and pirfenidone. Most differences were explained by model choice (fixed or random effects), choice of scale, endpoint definitions, inclusion of different studies, different lengths of follow-up, or access to unpublished data.

A substantive difference between the NMAs remains, however, with respect to conclusions regarding change from baseline FVC.

Further research is needed to determine:

1. Whether the SMD is appropriate in this population or whether a bivariate approach could be used [26];

2. The functional form of FVC over time to consider the viability of synthesising endpoints across different timepoints;

3. Whether the study populations are sufficiently homogeneous to fit a fixed effect model, whether random effects should be preferred, or whether meta-regression would be plausible;

4. The efficacy of the combined pirfenidone/nintedanib treatment. As this does not connect to the evidence network, a different methodology such as population matching would be required [27].

Finally, differences in patient characteristics may obscure difference in treatment effects, despite the judgement of similarity undertaken by three of the NMAs. A systematic review of prognostic factors in IPF could be conducted to determine the heterogeneity between studies, for example the severity of disease at enrolment. Our review demonstrates how differences in methodological approaches to an NMA can influence outcome. This has potential implications for the use of NMAs in clinical decision-making, in particular with an endpoint such as the FVC. To assist decision-makers, an exploration of efficacy of pirfenidone and nintedanib in real-world populations may be prudent.

Author Contributions: Conceptualization, D.A.S., E.L., J.L.C. and K.O.; methodology, D.A.S., E.L. and J.L.C.; validation, D.A.S., E.L. and J.L.C.; formal analysis, D.A.S.; investigation, E.L. and J.L.C.; writing-original draft 
preparation, D.A.S., E.L., J.L.C. and K.O.; writing-review and editing, D.A.S., E.L., J.L.C. and K.O.; visualization, D.A.S., E.L., J.L.C. and K.O.; project administration, E.L.

Acknowledgments: D.A.S. acknowledges the support of the NIHR Collaboration for Leadership in Applied Health Research and Care East Midlands (CLAHRC EM).

Conflicts of Interest: The authors report no conflict of interest

\section{References}

1. Swigris, J.J.; Stewart, A.L.; Gould, M.K.; Wilson, S.R. Patients' perspectives on how idiopathic pulmonary fibrosis affects the quality of their lives. Health Qual. Life Outcomes 2005, 7, 61. [CrossRef] [PubMed]

2. Bucher, H.C.; Guyatt, G.H.; Griffith, L.E.; Walter, S.D. The results of direct and indirect treatment comparisons in meta-analysis of randomized controlled trials. J. Clin. Epidemiol. 1997, 50, 683-691. [CrossRef]

3. Caldwell, D.M.; Ades, A.E.; Higgins, J.P. Simultaneous comparison of multiple treatments: Combining direct and indirect evidence. BMJ 2005, 331, 897-900. [CrossRef] [PubMed]

4. $\quad$ Dias, S.; Welton, N.J.; Sutton, A.J.; Ades, A.E. Evidence synthesis for decision making 1: Introduction. Med. Decis. Making 2013, 33, 597-606. [CrossRef] [PubMed]

5. Sutton, A.J.; Abrams, K.R. Bayesian methods in meta-analysis and evidence synthesis. Stat. Methods Med. Res. 2001, 10, 277-303. [CrossRef] [PubMed]

6. Perera, R.; Heneghan, C. Interpreting meta-analysis in systematic reviews. Evid. Based Med. 2008, 13, 67-69. [CrossRef]

7. Dias, S.; Sutton, A.J.; Welton, N.J.; Ades, A.E. Evidence synthesis for decision making 3: Heterogeneity-Subgroups, meta-regression, bias, and bias-adjustment. Med. Decis. Making 2013, 33, 618-640. [CrossRef]

8. Canestaro, W.J.; Forrester, S.H.; Raghu, G.; Ho, L.; Devine, B.E. Drug treatment of idiopathic pulmonary fibrosis: systematic review and network meta-analysis. Chest 2016, 149, 756-766. [CrossRef]

9. Fleetwood, K.; McCool, R.; Glanville, J.; Edwards, S.C.; Gsteiger, S.; Daigl, M.; Fisher, M. Systematic review and network meta-analysis of idiopathic pulmonary fibrosis treatments. J. Manag. Care Spec. Pharm. 2017, 23, s5-s16. [CrossRef]

10. Loveman, E.; Copley, V.R.; Scott, D.A.; Colquitt, J.L.; Clegg, A.J.; O’Reilly, K.M. Comparing new treatments for idiopathic pulmonary fibrosis-A network meta-analysis. BMC Pulm. Med. 2015, 15, 37. [CrossRef]

11. Loveman, E.; Copley, V.R.; Colquitt, J.L.; Scott, D.A.; Clegg, A.J.; Jones, J.; O’Reilly, K.M.; Singh, S.; Bausewein, C.; Wells, A. The effectiveness and cost-effectiveness of treatments for idiopathic pulmonary fibrosis: Systematic review, network meta-analysis, and health economic evaluation. BMC Pharmacol. Toxicol. 2014, 15, 63. [CrossRef] [PubMed]

12. Rochwerg, B.; Neupane, B.; Zhang, Y.; Garcia, C.C.; Raghu, G.; Richeldi, L.; Brozek, J.; Beyene, J.; Schünemann, H. Treatment of idiopathic pulmonary fibrosis: A network meta-analysis. BMC Med. 2016, 14, 18. [CrossRef] [PubMed]

13. Skandamis, A.; Kani, C.; Markantonis, S.L.; Souliotis, K. Systematic review and network meta-analysis of approved medicines for the treatment of idiopathic pulmonary fibrosis. J. Drug Assess. 2019, 8, 55-61. [CrossRef] [PubMed]

14. Huang, H.; Dai, H.P.; Kang, J.; Chen, B.Y.; Sun, T.Y.; Xu, Z.J. Double-blind randomized trial of pirfenidone in chinese idiopathic pulmonary fibrosis patients. Medicine 2015, 94, e1600. [CrossRef] [PubMed]

15. Ogura, T.; Taniguchi, H.; Azuma, A.; Inoue, Y.; Kondoh, Y.; Hasegawa, Y.; Bando, M.; Abe, S.; Mochizuki, Y.; Chida, K.; et al. Safety and pharmacokinetics of nintedanib and pirfenidone in idiopathic pulmonary fibrosis. Eur. Respir. J. 2015, 45, 1382-1392. [CrossRef] [PubMed]

16. Azuma, A.; Nukiwa, T.; Tsuboi, E.; Suga, M.; Abe, S.; Nakata, K.; Taguchi, Y.; Nagai, S.; Itoh, H.; Ohi, M.; et al. Double-blind, placebo-controlled trial of pirfenidone in patients with idiopathic pulmonary fibrosis. Am. J. Respir. Crit. Care Med. 2005, 171, 1040-1047. [CrossRef] [PubMed]

17. Taniguchi, H.; Ebina, M.; Kondoh, Y.; Ogura, T.; Azuma, A.; Suga, M.; Taguchi, Y.; Takahashi, H.; Nakata, K.; Sato, A.; et al. Pirfenidone in idiopathic pulmonary fibrosis. Eur. Respir. J. 2010, 35, 821-829. [CrossRef]

18. Noble, P.W.; Albera, C.; Bradford, W.Z.; Costabel, U.; Glassberg, M.K.; Kardatzke, D.; King, T.E., Jr.; Lancaster, L.; Sahn, S.A.; Szwarcberg, J.; et al. Pirfenidone in patients with idiopathic pulmonary fibrosis (CAPACITY): Two randomised trials. Lancet 2011, 377, 1760-1769. [CrossRef] 
19. King, T.E., Jr.; Bradford, W.Z.; Castro-Bernardini, S.; Fagan, E.A.; Glaspole, I.; Glassberg, M.K.; Gorina, E.; Hopkins, P.M.; Kardatzke, D.; Lancaster, L.; et al. A phase 3 trial of pirfenidone in patients with idiopathic pulmonary fibrosis. N. Engl. J. Med. 2014, 370, 2083-2092. [CrossRef]

20. Richeldi, L.; Costabel, U.; Selman, M.; Kim, D.S.; Hansell, D.M.; Nicholson, A.G.; Brown, K.K.; Flaherty, K.R.; Noble, P.W.; Raghu, G.; et al. Efficacy of a tyrosine kinase inhibitor in idiopathic pulmonary fibrosis. N. Engl. J. Med. 2011, 365, 1079-1087. [CrossRef]

21. Richeldi, L.; du Bois, R.M.; Raghu, G.; Azuma, A.; Brown, K.K.; Costabel, U.; Cottin, V.; Flaherty, K.R.; Hansell, D.M.; Inoue, Y.; et al. Efficacy and safety of nintedanib in idiopathic pulmonary fibrosis. N. Engl. J. Med. 2014, 370, 2071-2082. [CrossRef] [PubMed]

22. Chinn, S. A simple method for converting an odds ratio to effect size for use in meta-analysis. Stat. Med. 2000, 19, 3127-3131. [CrossRef]

23. Systematic Reviews in Health Care: Meta-Analysis in Context, 2nd ed.; Egger, M.; Davey Smith, G.; Altman, D.G., Eds.; BMJ Publishing Group: London, UK, 2001.

24. King, T.E., Jr.; Albera, C.; du Bois, R.M.; Bradford, W.; Costabel, U.; Noble, P.W.; Sahn, S.A.; Valeyre, D. The Effect of treatment with pirfenidone on longitudinal change in lung volume in patients with idiopathic pulmonary fibrosis (IPF): A meta-analysis of outcomes in four randomized controlled clinical trials. Am. J. Respir. Crit. Care Med. 2011, 183, A5302.

25. Nathan, S.D.; Albera, C.; Bradford, W.Z.; Costabel, U.; Glaspole, I.; Glassberg, M.K.; Kardatzke, D.R.; Daigl, M.; Kirchgaessler, K.U.; Lancaster, L.H.; et al. Effect of pirfenidone on mortality: Pooled analyses and meta-analyses of clinical trials in idiopathic pulmonary fibrosis. Lancet Respir. Med. 2017, 5, 33-41. [CrossRef]

26. Ades, A.E.; Lu, G.; Dias, S.; Mayo-Wilson, E.; Kounali, D. Simultaneous synthesis of treatment effects and mapping to a common scale: An alternative to standardisation. Res. Synth. Methods 2015, 6, 96-107. [CrossRef]

27. Phillippo, D.M.; Ades, A.E.; Dias, S.; Palmer, S.; Abrams, K.R.; Welton, N.J. Methods for population-adjusted indirect comparisons in health technology appraisal. Med. Decis. Making 2018, 38, 200-211. [CrossRef]

(C) 2019 by the authors. Licensee MDPI, Basel, Switzerland. This article is an open access article distributed under the terms and conditions of the Creative Commons Attribution (CC BY) license (http://creativecommons.org/licenses/by/4.0/). 